\title{
Mídia tática como conceito operativo nas artes visuais
}

Tactical media as an operative concept of visual arts

\author{
THIAGO SPÍNDOLA MOTTA FERNANDES \\ Universidade Federal do Rio de Janeiro, UFRJ - Brasil
}

\section{RESUMO}

Este artigo apresenta o conceito de mídia tática, seu surgimento nas formas de ativismo associadas à mídia, bem como suas raízes na ética punk e no pensamento de Michel de Certeau, com objetivo de identificar suas manifestações no campo das artes visuais, e em particular na arte contemporânea brasileira. Acreditamos que esse conceito, ainda pouco explorado por estudiosos da arte, pode ativar novos olhares para trabalhos artísticos que fazem uso subversivo e poético das mídias de massa, desviando-as de seus fins originais.

\section{PALAVRAS-CHAVE}

Mídia tática; arte contemporânea; ética punk.

\begin{abstract}
A B STR ACT
This article presents the concept of tactical media, its emergence in forms of activism associated with the media, as well as its roots in punk ethics and Michel de Certeau's thinking, with the aim of identifying its expressions in the visual arts, and particularly in contemporary Brazilian art. We believe that this concept, still not so much explored by art researchers, can activate new perspectives about artworks that produces subversive and poetic uses of mass media, diverting them from their original purposes.
\end{abstract}

\section{KEYWORDS}

Tactical media; contemporary art; punk ethics. 


\section{Introdução}

Estados Unidos, 30 de outubro de 1938. Véspera de Halloween. A 2a Guerra Mundial estava prestes a eclodir. O cenário era de tensão devido ao conflito eminente e aos refluxos da Grande Depressão de 1929, que ainda eram sentidos. A TV ainda dava seus primeiros passos enquanto o rádio vivia sua era de ouro, sendo o principal canal de comunicação sobre a situação europeia, além, é claro, dos desastres locais, como o caso do dirigível “Hinderburg”, que caíra sobre Nova Jersey matando dezenas de pessoas. Era comum a programação do rádio ser interrompida, dando lugar a boletins oficiais sobre notícias catastróficas. Já havia passado a época em que o rádio era visto como uma novidade fascinante, um modismo e, naquele momento, era uma necessidade. A credibilidade conquistada por esse meio era indiscutível.

Nesse contexto, Orson Welles realizou o que pode ser considerada uma das primeiras ações de mídia tática. Trata-se da transmissão radiofônica de uma adaptação do livro "A Guerra dos Mundos", de H. G. Wells, que devido ao grau de naturalidade com que foi realizada causou pânico em milhões de pessoas, que acreditavam estar vivenciando uma invasão alienígena. A ação, realizada com o grupo de teatro Mercury, resultou na sobrecarga de linhas telefônicas, aglomerações nas ruas, congestionamentos, etc. A transmissão teatralizada de obras literárias em programas de rádio não era uma novidade, mas Welles, que mais tarde se tornaria mundialmente conhecido como diretor do filme "Cidadão Kane", considerado uma das maiores obras da história do cinema, introduziu elementos que saíam do padrão da radiodifusão de obras ficcionais aos quais os ouvintes estavam acostumados. Além de efeitos sonoros, foi utilizada uma linguagem jornalística, que garantia maior grau de verossimilhança e credibilidade ao conteúdo narrado, que incluía depoimentos de supostos especialistas, autoridades, figuras políticas e cidadãos.

A ação de Welles foi capa de diversos jornais dos Estados Unidos e deixou um alerta sobre o poder de persuasão do rádio. O diretor fez uso do mais influente meio de comunicação de sua época como espaço performativo, de modo subversivo, criando um ruído em sua programação. Embora o termo mídia tática seja cunhado quase 60 anos depois e comumente seja associado ao hacktivismo ${ }^{1}$ e às estratégias que nascem com a popularização da internet, a ação de Welles demonstra que ações da mesma natureza subversiva precedem as novas tecnologias e podem ser executadas nos meios de comunicação hoje vistos como tradicionais, como o rádio e o jornal impresso.

A mídia tática, termo ainda pouco recorrente em pesquisas no campo das artes visuais, caracteriza-se, sobretudo, pelo uso das mídias para fins não comerciais e subversivos. Trata-se de um conceito que se firmou na década de 1990, na Europa e Estados Unidos, para denominar práticas baseadas na lógica "faça você mesmo" [do it yourself], presente na ética punk, como estímulo para a criação de novas formas de comunicação com o público.

1 União do hacking com o ativismo. Abrange ações que perturbam as operações de um site alvo na internet, mas não the causam danos graves. 


\section{Origens da mídia tática e primeiras discussões teóricas}

A popularização da internet e dos dispositivos digitais provocaram grandes transformações na maneira das pessoas se comunicarem. Nesse cenário, diversificam-se as formas de ativismo relacionado à mídia - midiativismo - com novas formas de confrontar o poder institucional na área de comunicação, sob influência de coletivos e movimentos de contracultura, além da ética hacker. No contexto em questão, associado sobretudo à Europa pós-queda do Muro de Berlim, surgem as primeiras discussões sobre mídia tática (FOLETTO, 2015).

Existem diferentes definições de mídia tática, mas pode-se estabelecer como marco inicial das discussões sobre esse conceito a primeira edição do "Next Five Minutes" (N5M), festival sobre arte, política, ativismo e mídia realizado em Amsterdã em 1993. Foram realizadas outras edições do N5M em 1996, 1999 e 2003 - mesmo ano em que foi realizado em São Paulo o "Festival Mídia Tática Brasil", inspirado no evento de Amsterdã.

A primeira edição do N5M tinha o objetivo de expor e debater vídeos independentes e produções audiovisuais de cunho político da segunda metade do século $X X$, tendo como tema central a ideia de televisão tática. Tal conceito foi ampliado, dando origem à noção de mídia tática, que foi tema da segunda edição do evento, realizada em 1996 (FOLETTO, 2015). Um texto publicado na seção de perguntas e respostas do site do festival (hoje desativado) e atualmente disponível no site "Tactical Media Files" (www.tacticalmediafiles.net), um dos principais arquivos em domínio público sobre mídia tática, afirma que esse termo designa o uso crítico e teorização das práticas midiáticas que recorrem a todos os tipos de novas e velhas mídias para alcançar uma variedade de objetivos não comerciais específicos e promover todos os tipos de questões políticas potencialmente subversivas.

Pense em ativistas que usam câmeras de vídeo digitais baratas e distribuem seus vídeos na internet. Pense em transmissores de rádio FM de baixa potência usados por ativistas antiglobalização. Pense em programadores de computador que desenvolvem softwares livres e de código aberto. Pense na tecnologia sem fio que fornece a comunidades inteiras acesso barato à Internet de banda larga. Pense em artistas midiáticos que expressam suas preocupações sobre questões políticas atuais. E pense em investigações sobre política e economia das tecnologias da informação (website TACTICAL MEDIA FILES).

Dessa maneira, entende-se que embora o conceito de mídia tática surja com as revoluções ocasionadas pela popularização da internet e das tecnologias digitais, esse tipo de ação pode ser realizado por meio de velhas mídias.

Tal "utilização crítica" é exemplificada no site da segunda edição do festival N5M pela atuação de ativistas dos movimentos altermundialistas, equivocadamente chamados de antiglobalização; a ação de ativistas que veiculam programas de rádio em transmissores de baixa potência ou daqueles que elaboram vídeos com câmeras 
digitais e distribuem sua produção pela Internet. Outras práticas listadas são o trabalho de programadores de software livre e de código aberto, a arte midiática e pesquisas sobre a política e a economia das tecnologias da informação. Destacam-se ainda as tecnologias sem fio que viabilizam acesso barato à Internet de banda larga para comunidades (CLINIO, 2013, p. 171).

A primeira conceituação formal da mídia tática aparece no texto "O ABC da Mídia Tática", uma espécie de manifesto publicado por Geert Lovink e David Garcia em 1997 na plataforma "Net.time". O texto foi traduzido e difundido no Brasil pelo crítico Ricardo Rosas, por meio da plataforma "Rizoma.net", que hoje encontra-se desativada. Segundo Lovink e Garcia,

Mídias Táticas são o que acontece quando mídias baratas tipo "faça você mesmo", tornadas possíveis pela revolução na eletrônica de consumo e formas expandidas de distribuição (do cabo de acesso público à internet), são utilizadas por grupos e indivíduos que se sentem oprimidos ou excluídos da cultura geral. As mídias táticas não só reportam fatos, mas também nunca são imparciais: elas sempre participam e é isso o que mais que qualquer coisa as separa das mídias dominantes (GARCIA; LOVINK, 2002, p. 139).

Os autores citam como referência para a conceituação da mídia tática o livro "A invenção do cotidiano", do historiador francês Michel De Certeau, publicado originalmente em 1980. A obra trata de práticas e táticas criativas adotadas pela cultura popular por meio de textos e artefatos que a rodeiam, transferindo a ênfase das representações em si para os usos das representações.

Certeau traça distinções entre tática e estratégia, essenciais para o conceito de mídia tática. Estratégia seria "o cálculo (ou a manipulação) das relações de forças que se torna possível a partir do momento em que um sujeito de querer e poder (uma empresa, um exército, uma cidade, uma instituição científica) pode ser isolado" (CERTEAU, 1998, p. 99), enquanto a tática, por oposição, seria “a ação calculada que é determinada pela ausência de um próprio" (CERTEAU, 1998, p. 100). Ou seja, a tática, diferentemente da estratégia, é a arte do fraco, daquele que "não tem por lugar senão o do outro" (CERTEAU, 1998, p. 100). Enquanto a estratégia possui lugar próprio, autônomo, que permite controlar, planejar e capitalizar as vantagens adquiridas, a tática tem que jogar com o terreno que lhe é imposto, dentro do campo de visão do inimigo, no espaço por ele controlado, aproveitando "ocasiões".

Ele [Certeau] descreveu o processo de consumo como um conjunto de táticas pelas quais o fraco faz uso do forte. Ele caracterizou o usuário (um termo que ele preferiu a consumidor) rebelde como tático e o presumido produtor (no qual ele inclui autores, educadores, curadores e revolucionários) como estratégico. Estabelecer esta dicotomia permitiu a ele produzir um vocabulário de táticas rico e complexo o bastante para equivaler a uma estética reconhecível e distinta. Uma 
estética existencial. Uma estética da apropriação, do engano, da leitura, da fala, do passeio, da compra, do desejo. Truques engenhosos, a astúcia do caçador, manobras, situações polimórficas, descobertas prazerosas, tão poéticas quanto guerreiras (GARCIA; LOVINK, 2002, p. 139-140).

Em seu livro, Certeau exemplifica tais subversões na relação entre indígenas e colonizadores espanhóis, pensando como os primeiros se utilizavam da ordem dominante para exercer seu poder:

Há muito tempo que se tem estudado que equívoco rachava, por dentro, o "sucesso" dos colonizadores espanhóis entre as etnias indígenas: submetidos e mesmo consentindo na dominação, muitas vezes esses indígenas faziam das ações rituais, representações ou leis que thes eram impostas outra coisa que não era aquela que o conquistador julgava obter por elas. Os indígenas as subvertiam, não rejeitandoas diretamente ou modificando-as, mas pela sua maneira de usá-las para fins em função de referências estranhas ao sistema do qual não podiam fugir (CERTEAU, 1998, p. 39).

O conhecimento da dicotomia tática/estratégia, analisada por Certeau, ajudou Levink e Garcia a nomear uma classe de produtores conscientes do valor de inversões temporárias no fluxo de poder. Esses agentes tornam-se criadores de espaços, canais e plataformas para tais inversões trabalho designado mídia tática - que rompem com as dicotomias amador/profissional, alternativo/ popular e até mesmo público/privado.

Não podemos deixar de pontuar os esforços do crítico e ativista cearense Ricardo Rosas, um dos principais teóricos brasileiros da mídia tática, embora ainda seja pouco citado, sobretudo em pesquisas em artes visuais. Rosas, falecido em 2007, foi um dos organizadores do Festival Mídia Tática Brasil em 2003 e de outros importantes eventos, além de escrever e traduzir diversos textos sobre coletivismo artístico e mídia tática. Sua contribuição, sobre a qual não nos aprofundaremos neste texto, merece atenção especial em um artigo exclusivo. Outra grande referência nacional para o assunto é o livro "Arte-veículo: intervenções na mídia de massa brasileira”, escrito pela pesquisadora e curadora Ana Maria Maia. A autora realizou um levantamento exaustivo de artistas e grupos brasileiros que se apropriaram das mídias de massa para a realização de seus trabalhos entre as décadas de 1950 e 2010, destacando particularidades na produção de cada geração, bem como questões sociológicas pertinentes a cada período analisado. A publicação se desdobrou em uma exposição coletiva realizada em 2018 no Sesc Pompéia, em São Paulo, contando com 47 artistas e grupos.

\section{Não odeie a mídia, torne-se a mídia}

A lógica "faça você mesmo", apontada no texto de Lovink e Garcia, ganha projeção na década de 1960, com a difusão de tecnologias de informação e comunicação baratas e fáceis de usar e é apropriada na década seguinte pela cultura punk. O punk se difere do rock'n'roll tradicional não 
apenas no som, mas na maneira como as bandas dirigem seu próprio negócio e lidam com o público. Craig O’Hara, no livro “A filosofia do punk: mais do que barulho", afirma que entre as bandas punks não há competição, mas colaboração entre si, e que o espírito do empreendimento punk é o "faça você mesmo", como extensão dos princípios anarquistas, calcados na cooperação para a construção de um futuro mais produtivo, criativo e agradável. Dessa maneira, os punks organizam sua própria diversão, sem visar lucro, organizando shows, passeatas, lançando discos, livros e fanzines. O'Hara relata:

Empresários de bandas punks, são raros e, até recentemente, contratos para discos e shows eram praticamente inexistentes. Os discos são vendidos por abaixo do preço médio geral e diretamente pelas bandas e poucas lojas. A influente banda Crass foi talvez a primeira a vender seus discos mais barato e até usava os lucros para ajudar outras bandas a gravarem suas músicas (O’HARA, 2005, p. 158).

Segundo O'Hara, os punks rejeitam bandas que assinam com grandes gravadoras com justificativa de levar sua mensagem a um público maior e consideram tal ato mera transformação de rebeldia em dinheiro, que acaba por esvaziar o conteúdo de suas músicas. 0 autor conta que o sucesso de bandas inglesas, como The Clash e Sex Pistols, deixou grandes gravadoras com desejo de contratar o maior número possível de bandas "rebeldes" para lucrar em cima da onda punk.

Em meados da década de 1970, com o crescimento das cenas punk em Nova York e Londres, surgem os fanzines - também chamados zines - calcados na lógica "faça você mesmo". Fanzines são o principal meio de comunicação entre punks. Trata-se de publicações em baixa tiragem, de aparência amadora - em comparação com revistas profissionais -, feitas, em maioria, por meio de copiadoras e grampeadas, sem numeração de páginas, sem direitos autorais e sem nenhuma chance de rentabilidade. Tais publicações geralmente tratam de música e política. O’Hara afirma que para ser editor de um fanzine só é necessário ter acesso a uma copiadora barata e ânsia de expressar opiniões, ideias ou pensamentos. Uma vez que as lojas não se interessam por publicações que geram baixo público ou possuem público irrisório, fanzines são distribuídos por correio e só mais tarde, com a explosão dessa mídia em termos de quantidade e qualidade, lojas em todos os Estados Unidos passaram a aceitar tais publicações para venda e exposição em suas gôndolas de jornais e revistas.

Em sua dissertação de mestrado, André Mesquita (2008) lembra que entre as décadas de 1960 e 1970, quando se firmava a ética "faça-você-mesmo", no Brasil surgiam proposições de artistas que já adotavam essa lógica, como as instruções de Lygia Clark para os "Objetos relacionais”, as proposições de Hélio Oiticica para se fazer um "Parangolé" e, seguindo caminho mais próximo da mídia tática, as instruções de Cildo Meireles para criar suas “Inserções em circuitos ideológicos”.

Jello Biafra, vocalista da banda de punk rock norte americana Dead Kennedys, resume a ética punk do "faça você mesmo" na frase "não odeie a mídia, torne-se a mídia". Tal afirmação, que se relaciona aos modos de produção e circulação de conteúdo adotados pelos punks, coloca o público no lugar do produtor. A frase de Biafra dá abertura para se pensar a criação de novas mídias 
ou a apropriação dos veículos existentes para benefício próprio, relacionando-se às ideias da mídia tática. Se a mídia hegemônica causa revolta, ela pode ser combatida ou contestada por meio de seus próprios recursos, e é a isso que se propõem os ativistas da mídia tática.

\section{Mídia tática e arte contemporânea}

A categoria mídia tática ganha diferentes desdobramentos no campo das artes visuais: imagens que se confundem com anúncios publicitários, mas, na verdade, não vendem nada - e em vez disso carregam conteúdo poético; intervenções artísticas clandestinas ou com caráter de factoide nos jornais, TV, revistas e outros meios de comunicação; a reapropriação crítica de signos do mundo da publicidade; desvios e alterações efetuadas em mídias de sinalização e comunicação, etc.

A mídia tática é recorrente em ações de artistas e coletivos de cunho estético-político, dentre os quais podemos destacar o grupo carioca Tupinambá Lambido, em atividade desde 2016, cujas ações lançam mão de cartazes publicitários com conteúdo crítico a figuras da política brasileira e grandes corporações nacionais (figuras 1 e 2). Mas nas artes visuais, a mídia tática não é restrita apenas àqueles agentes diretamente ligados a formas de ativismo (ou artivismo, como alguns chamam), como também engloba ações de cunho poético, conceitual e experimental. Neste caso, destacamos a ação urbana experimental Atrocidades Maravilhosas, desenvolvida por um grupo de artistas que seria o primeiro a explorar o cartaz lambe-lambe como meio artístico no Rio de Janeiro (no ano 2000). Seus efeitos são ruídos na paisagem e na lógica da propaganda, uma vez que os lambe-lambes artísticos eram instalados em espaços públicos onde costumava-se encontrar, em vez disso, anúncios publicitários. A dupla Poro, de Belo Horizonte (MG), segue um caminho similar ao produzir suas "Faixas de anti-sinalização" (figura 3), desde 2009, com conteúdo de cunho poético, como as frases "Perca tempo", "Veja através" e "Atravesse as aparências". 0 trabalho torna visíveis aspectos da vida acelerada dos grandes centros urbanos. Em outra de suas intervenções urbanas, a dupla distribui panfletos que ensinam "10 maneiras incríveis de perder tempo". 

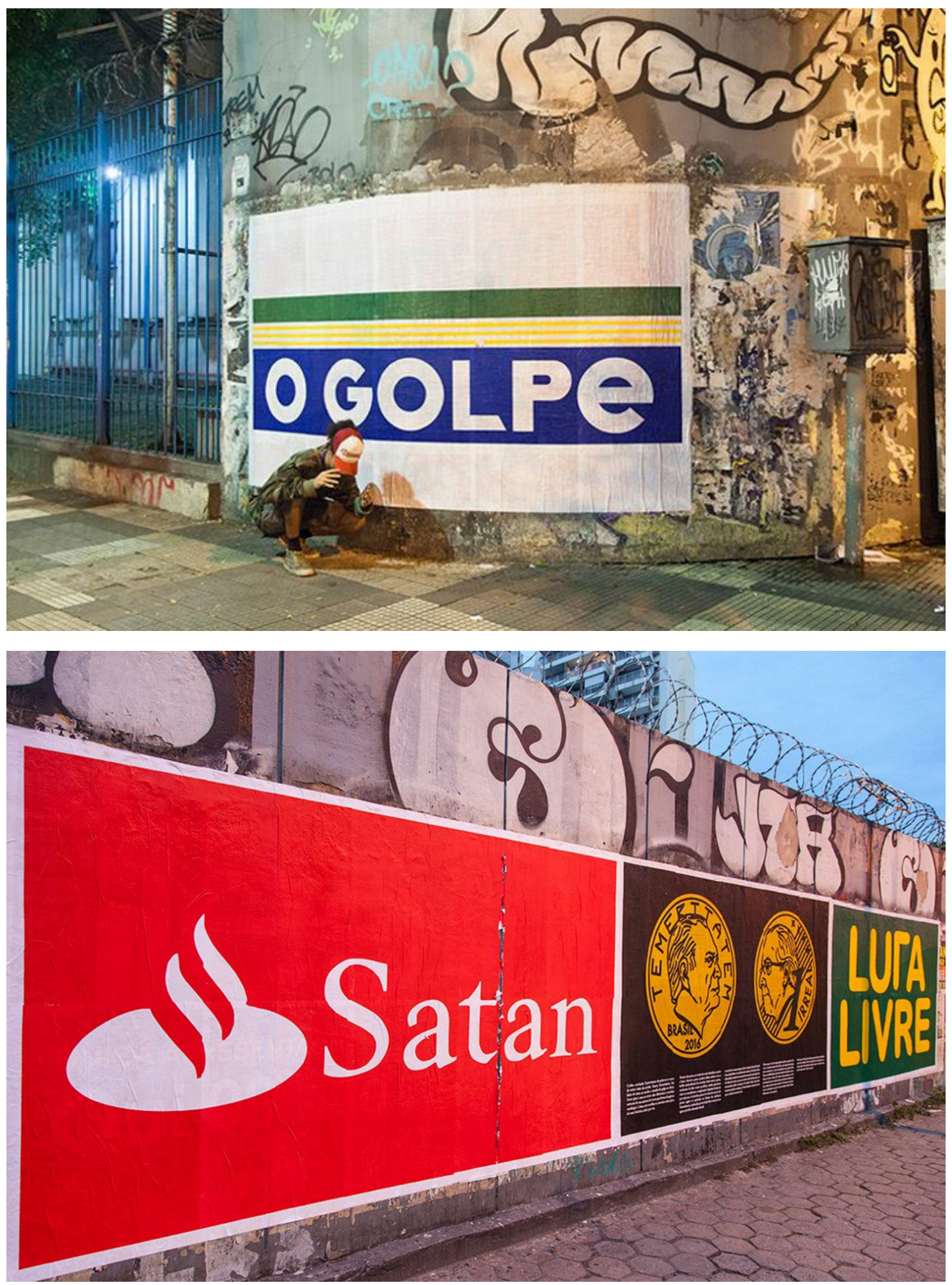

Figuras 1 e 2 - Cartazes do grupo Tupinambá Lambido, 2017-2018.

Fonte: arquivo do grupo 


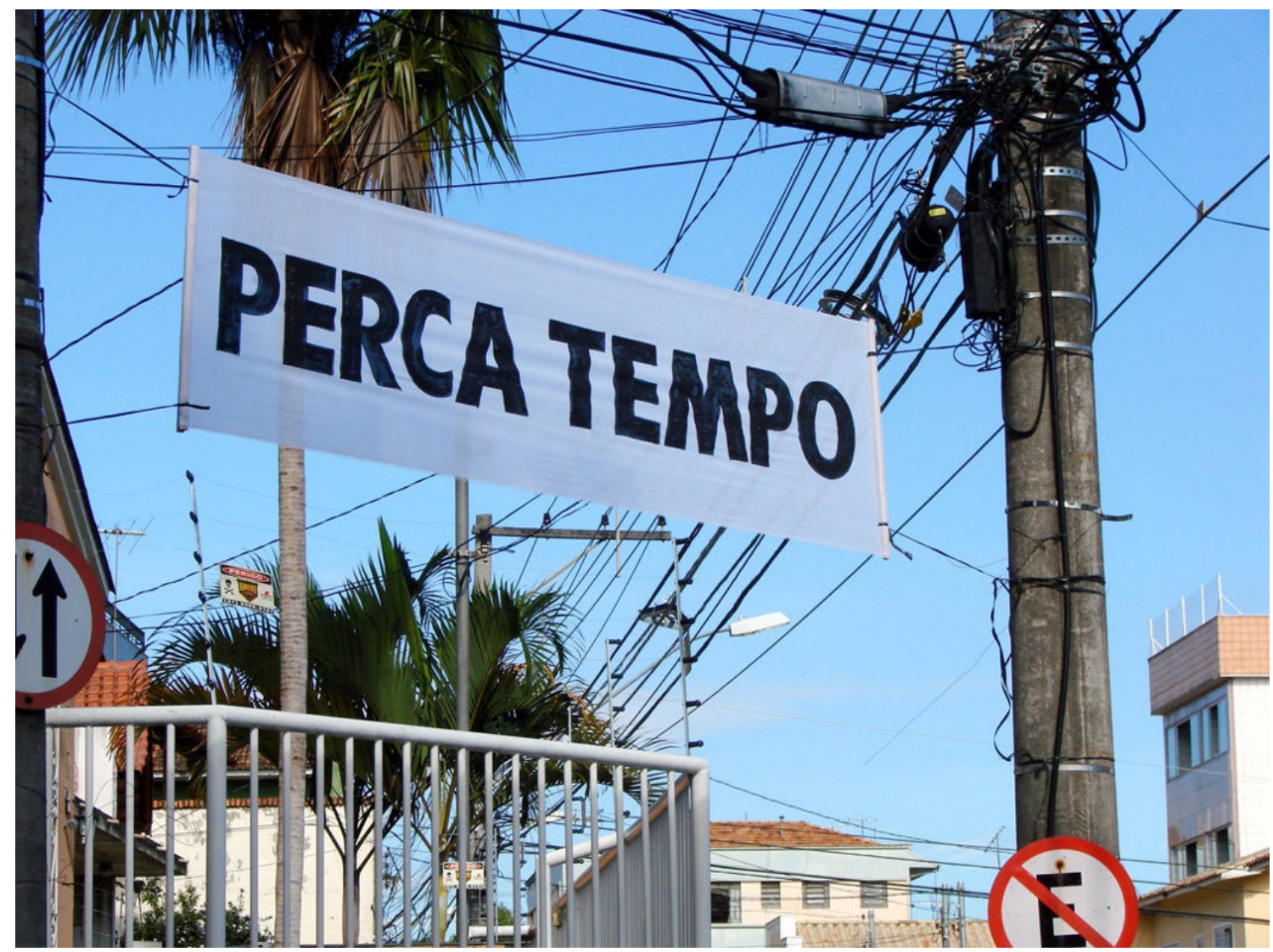

Figura 3 - Poro, Faixas de anti-sinalização, 2009.

Fonte: https://poro.redezero.org/intervencao/faixas-de-anti-sinalizacao/

Também chamamos de mídia tática algumas táticas de visibilidade adotadas por artistas que se veem à margem do circuito oficial de arte (formado por museus, galerias, etc.) e que possuem pouca ou nenhuma representação no espaço legitimador das mídias de massa. No ano 2000, o artista carioca Ducha realizou um trabalho de intervenção urbana conhecido como "Cristo Vermelho". Na noite de 26 de maio daquele ano, com a ajuda de amigos, Ducha burlou a segurança do Cristo Redentor e inseriu folhas de gelatina vermelha sobre os holofotes do monumento, colorindo-o durante alguns minutos. Sua proposta de intervenção fazia parte do primeiro "Prêmio Interferências Urbanas", mas havia sido vetada pela Arquidiocese. O artista, contudo, a realizou de forma clandestina, contrariando a decisão tomada pela Igreja Católica, e imediatamente foi acionada a Rio Luz, empresa responsável pela iluminação de espaços públicos da cidade, para retirar a gelatina e interromper a intervenção. 


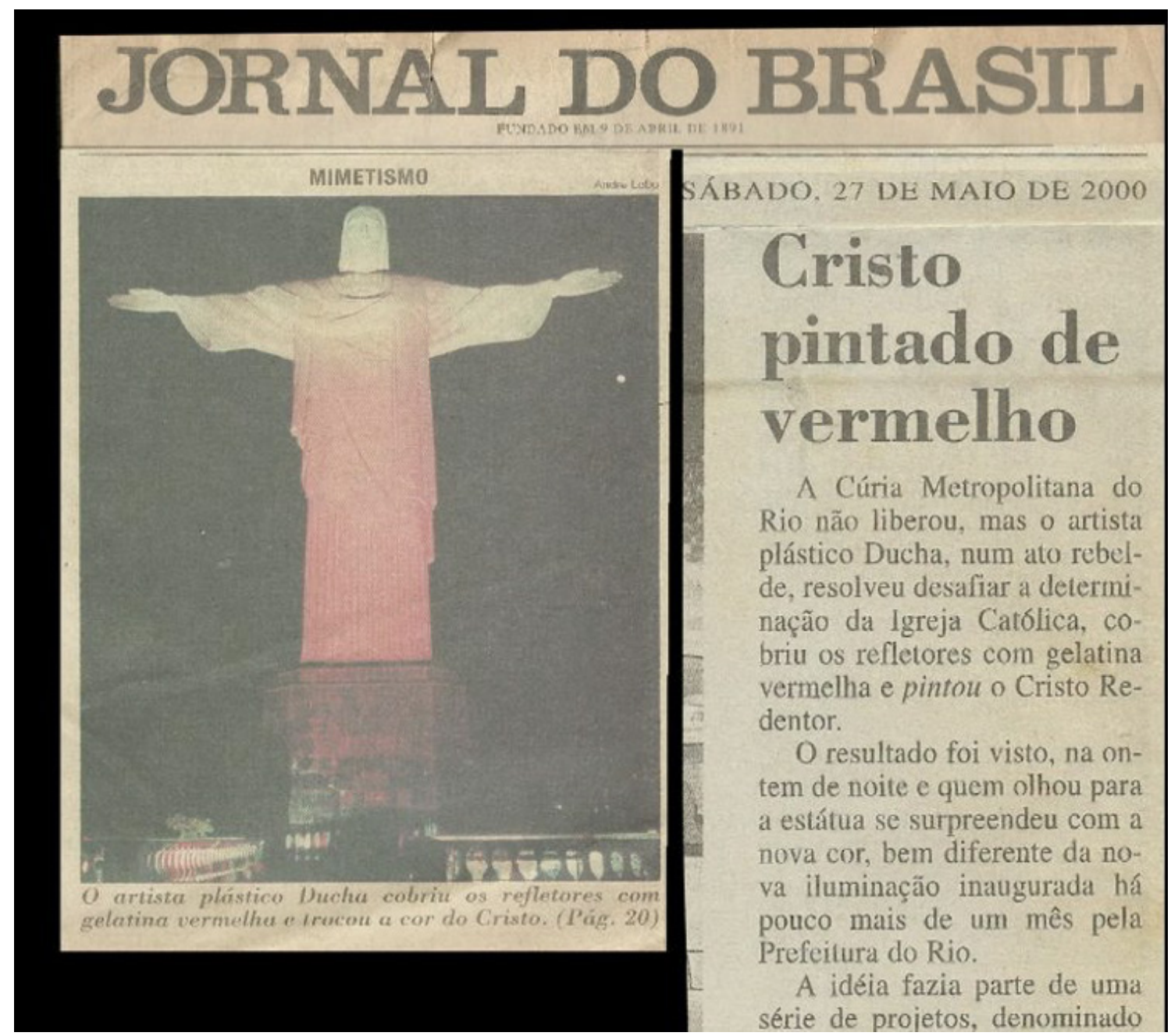

Figura 4 - Jornal do Brasil, 27 de maio de 2000 (recortes da capa e da matéria sobre o "Cristo Vermelho" de Ducha). Fonte: http://www.brasilvisual.art.br/gallery/intervencao-urbana/

O “Cristo Vermelho" de Ducha ficou visível durante cerca de 45 minutos, mas sua ação não terminou aí: o artista ligou imediatamente para o Jornal do Brasil informando sobre a alteração que realizou na cor do monumento e, no dia seguinte, uma fotografia de seu trabalho estampava a capa do jornal (figura 4). Dessa maneira, Ducha utiliza a imprensa a favor de si, garantindo maior duração e circulação de seu trabalho clandestino e efêmero. A ligação de Ducha para o Jornal do Brasil pode ser compreendida como um ato performativo e a circulação da imagem na mídia impressa como a essência dessa ação, enquanto a iluminação do monumento poderia ser considerada apenas parte do processo. $\mathrm{O}$ trabalho é germinado como intervenção urbana, mas ganha forma ao lançar mão de um artifício da mídia tática.

Ducha faz parte de uma geração de artistas da virada do século XXI que tomou as ruas como campos de ação para a realização de manifestações artísticas efêmeras. Diante da fragilidade do circuito artístico brasileiro naquele momento, além das intervenções urbanas, se disseminou 
no país um grande número de iniciativas coletivas de artistas e espaços alternativos de exposição, motivados pela inconformidade ou incompatibilidade de certos artistas com o circuito institucional. Uma vez que não havia um circuito que acolhesse a todos os artistas, aqueles que não conseguiam se inserir no restrito sistema das galerias de arte, museus e outras instituições legitimadoras, tiveram de criar seus próprios circuitos. Considerando esse contexto, podemos compreender que, além da possibilidade de estender a duração de um trabalho efêmero e fazê-lo circular, ao ligar para o Jornal do Brasil, Ducha é beneficiado pelo poder da mídia de massa de atribuir valor e legitimidade, como conta a crítica de arte Marisa Flórido Cesar:

Cristo vermelho parece transitar entre as várias concepções e abordagens relacionadas à tradição escultórica e sua migração ao campo ampliado: intervém fisicamente em um monumento e seu lugar, infiltra-se estratégica e criticamente na rede de circuitos discursivos em diversos campos de poder, como nas instituições (religiosas, estatais, artísticas) e na mídia. Se "público" tornou-se o campo midiático no qual a natureza de um fato é determinada e legitimada, Ducha realiza a ação buscando ganhar representação justamente aí. Se a mídia tem poder de conceber valor de verdade, ainda que por quinze minutos, como legitimar algo como arte além de seu protegido circuito? (CESAR, 2014, p. 35

A mídia de massa, como um espaço legitimador, é invadida pelo artista que antes não tinha espaço de destaque nela. 0 poder da mídia, de conceber valor de verdade - visto na ação realizada por Orson Welles por meio do rádio em 1938 -, é o que amplia a dimensão pública da ação de Ducha.

Em sua dissertação de mestrado, Anne Clinio (2011) lista uma série de ações consideradas integrantes do campo da mídia tática por diferentes teóricos, algumas das quais vemos serem adotadas por artistas contemporâneos, como o détournement e o culture jamming.

Détournment é uma palavra que em francês significa desvio, direção ou ainda sequestro. Na mídia tática designa uma prática conhecida devido a seu uso pelos situacionistas, que consiste em qualificar produtos ou processos cujo objetivo original foi alterado, tomando direção oposta. Tal é a prática adotada por Ducha, ao se apropriar de um jornal para torna-lo palco de uma ação artística - em vez de realiza-la em um "espaço de arte". Podem também ser inseridas nesta categoria as “Inserções em circuitos ideológicos” (1970-1976) de Cildo Meireles, uma vez que o artista transforma garrafas de Coca-Cola e cédulas de dinheiro em veículos de comunicação para mensagens tidas como subversivas. Ou ainda ações de grupos como Atrocidades Maravilhosas e Poro, que provocam desvios nos usos de cartazes, panfletos e faixas de sinalização. No contexto internacional, alguns dos principais destaques são os trabalhos da artista Barbara Kruger e o coletivo Guerrila Girls, que lançam mão de mídias publicitárias como cartazes e outdoors. 


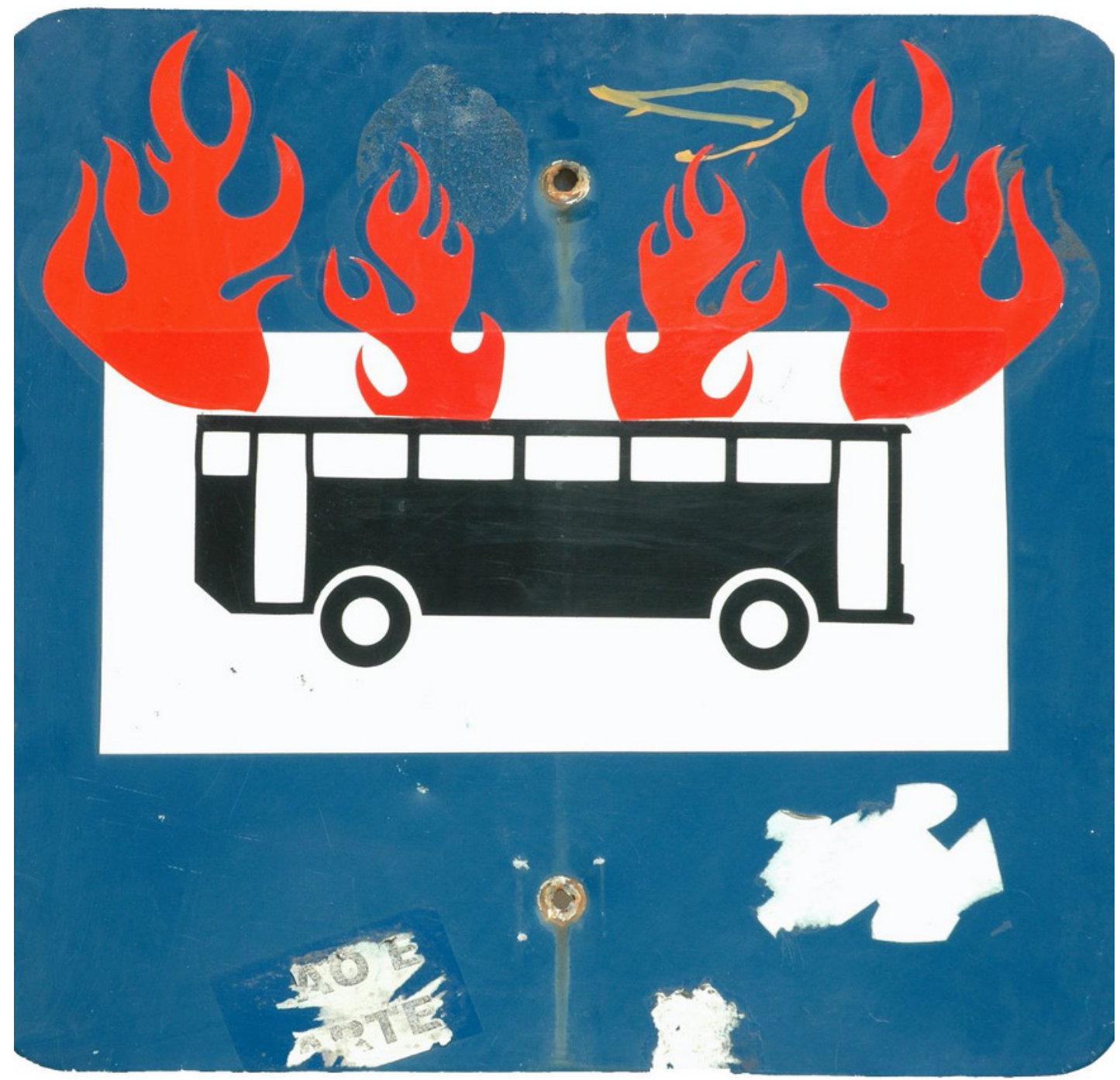

Figura 5 - Guga Ferraz, Ônibus incendiado, 2003. Fonte: arquivo do artista

O artista carioca Guga Ferraz é conhecido por suas táticas de desvio em placas de sinalização. O exemplo mais notável é a interferência que fez em placas de pontos de ônibus em 2003 (figura 5), quando colou sobre as mesmas adesivos em formato de chamas, como maneira de alertar a população sobre os recorrentes incêndios criminosos a veículos que aconteciam naquele ano. Trata-se de uma ação-vírus na qual o artista altera o significado da imagem: além de sinalizar o local onde os ônibus realizam suas paradas, a placa passa a informar sobre a onda de violência que toma o Rio de Janeiro.

Culture jamming é uma prática que também recontextualiza imagens, elementos gráficos e mensagens, mas tem como alvo privilegiado corporações multinacionais, apropriação do espaço público e discurso publicitário falacioso. Entre as principais táticas dessa modalidade estão a alteração de campanhas publicitárias e criação de notícias falsas. No campo da arte, alguns dos maiores expoentes desta categoria são o britânico Banksy e o norte-americano Ron English, 
mundialmente conhecidos por suas imagens satíricas e subversivas que lançam mão da linguagem da publicidade e de alguns dos maiores símbolos do capitalismo de maneira crítica - Banksy por meio do grafite, principalmente, e English por meio de outdoors (figura 6) e outras mídias publicitárias. Seguindo um caminho similar, no contexto de ações de protesto contra o impeachment da expresidenta Dilma Rousseff, o coletivo Tupinambá Lambido espalhou em muros do Rio de Janeiro grandes cartazes que recriam os logotipos do jornal O Globo e do banco Santander, alterando suas inscrições, respectivamente, para 0 Golpe e Satan (figuras 1 e 2). Por meio de ações como essa, o grupo buscava atingir a imagem de grandes corporações apoiadoras ou beneficiárias do processo que tirou Dilma do poder.

É importante pontuar que o détournement e o culture jamming são táticas que apresentam similaridades, e um mesmo trabalho artístico pode se situar nas duas categorias. Um outdoor que satiriza o logotipo ou mascote de uma grande corporação, por exemplo, é uma ação de culture jamming na medida em que recontextualiza ou deforma um elemento gráfico ou uma mensagem, mas também é um détournement, por propor um desvio em uma mídia publicitária (o outdoor) transformando-a em uma mídia artística ou anti-publicitária.

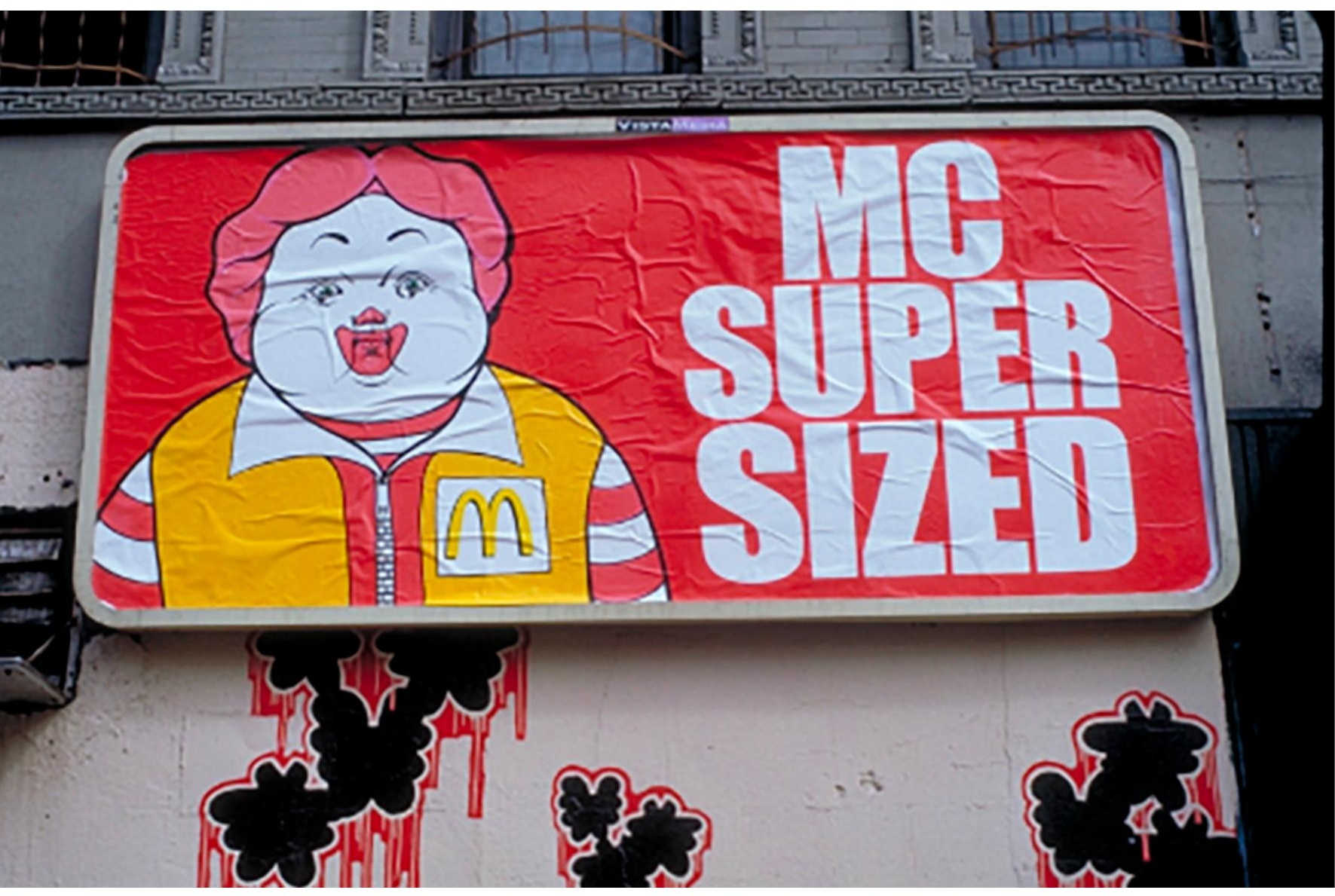

Figura 6 - Outdoor produzido por Ron English (sem data). Fonte: http://tiscoart.blogspot.com/ 
Ações que seguem a direção do discurso publicitário falacioso e das notícias falsas, apropriam-se do poder persuasivo e legitimador das mídias de massa. É onde podemos situar a ação performativa de Orson Welles no rádio em 1938, como também uma ação do artista cearense Yuri Firmeza, que em 2006 fez circular nos principais jornais de Fortaleza matérias sobre a suposta exposição de um "grande artista" japonês chamado Souzousareta Geijutsuka, que seria realizada no Museu de Arte Contemporânea do Ceará. Mas o evento não passava de um factoide criado por Firmeza, que também inventara o artista japonês. Souzousareta Geijutsuka jamais existiu fora de seu projeto artístico e das páginas dos jornais. A ação performativa foi realizada com apoio do museu, que assumiu a divulgação da falsa exposição, surpreendendo o público que esteve presente na abertura. A ação de Firmeza chama atenção para o poder legitimador da imprensa, capaz de gerar grande expectativa e atrair uma quantidade numerosa de pessoas para a exposição de um artista que sequer existe.

Pode-se citar também as intervenções de Paulo Bruscky e Antonio Manuel em jornais nos anos 1970. O pernambucano Paulo Bruscky realizou (e ainda realiza) diversas intervenções em classificados de jornais, entre elas o anúncio de uma máquina de registrar sonhos com filmes, que possibilita ao consumidor assistir a seus sonhos enquanto tomava café da manhã. 0 anúncio fictício de Bruscky, veiculado em 1977, subverte a lógica publicitária daquele espaço e aparece no meio de anúncios de outras máquinas, causando estranhamento no leitor do jornal. Já Antonio Manuel teve acesso à arte-final do jornal $O$ Dia e pôde substituir imagens e textos, criando tiragens alternativas da publicação - que levou pessoalmente às bancas e misturou a outros exemplares - intercalando notícias reais e ficções de conteúdo absurdo. Tais ações culminaram na série "Clandestinas" (1973). 0 mesmo artista realizou o trabalho "De 0 a 24 horas" (1973), que consiste em um encarte incorporado a um jornal, reunindo trabalhos pensados para sua exposição no Museu de Arte Moderna do Rio de Janeiro, cancelada pelos próprios organizadores por temerem que ela pudesse gerar situações problemáticas ao museu e ao artista, considerando a repressão dos militares naquele momento de ditadura. A ação de Antonio Manuel resultou em uma exposição de 24 horas, tempo de duração de um jornal nas bancas, e aconteceu exclusivamente em suas páginas. Em uma nota incluída no encarte, o artista afirma que "o espaço do MAM, das Galerias, tornou-se pequeno em relação aos veículos de massa" (O JORNAL, 15 de julho de 1973, p. 24).

Vemos, portanto, que a mídia tática é um conceito amplo, que abarca uma diversidade de práticas entre as quais algumas são mais frequentemente adotadas pelo campo da arte do que outras. $^{2}$

Outros termos tentam dar conta de intervenções artísticas nas mídias de massa. 0 pesquisador brasileiro Arlindo Machado, em seu livro Arte e mídia, publicado em 2007, fala sobre generalização do vocábulo artemídia, como forma aportuguesada do inglês media arts, para designar "formas de expressão artística que se apropriam dos recursos tecnológicos das mídias e da indústria do entretenimento em geral, ou intervêm em seus canais de difusão, para propor alternativas

2 Para o conhecimento das demais práticas dos ativistas da mídia tática, além daquelas comumente adotadas no campo da arte, conferir a dissertação de Clinio (2011) e o artigo de Foletto (2015). 
qualitativas" (MACHADO, 2007, p. 5). Inclui-se nessa categoria, segundo Machado, intervenções críticas em meios de comunicação de massa, bem como manifestações artísticas realizadas por meio da apropriação de recursos tecnológicos recentemente desenvolvidos nos campos da eletrônica, informática e engenharia biológica. Trata-se, portanto, de um termo mais abrangente, que engloba e extrapola expressões anteriores como arte \& tecnologia, artes eletrônicas, arte-comunicação, poéticas tecnológicas, etc.

Machado ressalta que a arte sempre foi produzida com os meios de seu tempo, apropriandose das tecnologias disponíveis, como, por exemplo, a relação de Edgar Degas com a fotografia e a de Marcel Duchamp com a cronofotografia na obra "Nu descendo uma escada" (1912). Mas o autor compreende que a apropriação que a arte faz dos aparatos tecnológicos que lhe são contemporâneos se difere do uso dos mesmos por outros setores da sociedade, como a indústria e bens de consumo. $\mathrm{Na}$ medida em que tais aparelhos são projetados para fins objetivos, a perspectiva artística lhe desvia de seus interesses originais. Machado chama atenção para artistas que operam fora das possibilidades programadas e previsíveis desses meios, reinventando radicalmente seus programas e finalidades. $\mathrm{O}$ que se chama artemídia, portanto, é produzido dentro dos meios econômicos vigentes, mas segue a direção contrária deles.

De maneira similar à visão de Machado, ao inserir trabalhos de arte na categoria mídia tática, chamamos atenção para seu caráter subversivo. Destacamos sua capacidade de interferir nos fluxos de poder e seu potencial viral. Essas táticas criativas propõem inversões nos veículos de comunicação, como também nos signos por eles emitidos.

\section{Considerações finais}

Com a migração da arte do espaço privado dos museus e das salas de concerto para o espaço público e turbulento da TV, internet ou ainda do ambiente urbano, seu estatuto e alcance são modificados e são possibilitadas novas formas de inserção social. Assim como Walter Benjamin (2012) afirma que com a reprodução técnica a arte deixa de ter uma função parasitária para ter uma função política, é possível pensar nos meios de comunicação de massa como agentes potencializadores de difusão, na medida em que vivemos em uma sociedade de base tecnocrática. Formas singulares de visualidade se manifestam nos trabalhos de Ducha, Paulo Bruscky e Antonio Manuel, por exemplo, que se apresentam nos jornais. Elas se diferem daquelas obras apresentadas em "lugares da arte", sobretudo pela maneira como se aproximam do público - em vez de deixar o público ir até elas - e pegam-no de surpresa. Um choque similar é causado por aqueles trabalhos que desconstroem as imagens publicitárias, já enraizadas no cotidiano, e chamam atenção para sentidos implícitos nas mesmas.

Concluímos que o conceito de mídia tática, mais recorrente em pesquisas nas áreas de comunicação e de ciência da informação, pode oferecer importantes contribuições para pesquisas no campo das artes visuais, e em particular nos estudos sobre arte contemporânea brasileira. Esperase, com este texto, fomentar novas discussões e ativar novos olhares para trabalhos artísticos que fazem uso subversivo e poético das mídias de massa. 


\section{Referências}

BENJAMIN, Walter. A obra de arte na era de sua reprodutibilidade técnica. In: CAPISTRANO, Tadeu (org.). Benjamin e a obra de arte: técnica, imagem e percepção. Rio de Janeiro: Contraponto, 2012.

CÉSAR, Maria Flórido. Nós, o outro, o distante na arte contemporânea brasileira. Rio de Janeiro: Circuito, 2014.

CLINIO, Anne. Mídias táticas no Brasil: dinâmicas de informação e comunicação. Dissertação (Mestrado em Ciência da Informação). Rio de Janeiro: Universidade Federal do Rio de Janeiro, 2011.

CLINIO, Anne. A ação política no cotidiano: a mídia tática como conceito operacional para pesquisas em mídia, cotidiano e política. In: Mídia e Cotidiano. Niterói: Universidade Federal Fluminense, n. 1, p. 169-188, 2013.

CERTEAU, Michel de. A invenção do cotidiano, 3ª ed. Petrópolis: Vozes, 1998.

O’HARA, Craig. A filosofia do punk: mais do que barulho. São Paulo: Radical Livros, 2005.

FOLETTO, Leonardo. Mídia tática e cultura hacker: aproximações no contexto brasileiro. In: Anais do II Congresso Internacional de Net-Ativismo. São Paulo: ECA-USP, 2015.

GARCIA, David, LOVINK, Geert. O ABC da mídia tática. In: ROSAS, Ricardo, SALGADO, Marcus (org.). Rizoma - Intervenção, p. 139-141, 2002. Disponível em: http://desarquivo.org/node/1228/. Acesso: 08/05/2020.

MACHADO, Arlindo. Arte e mídia. Rio de Janeiro: Zahar, 2007.

MESQUITA, André Luiz. Insurgências poéticas: arte ativista e ação coletiva (1990-2000). Dissertação (Mestrado em História Social). São Paulo: USP, 2008.

O JORNAL. Exposição de Antonio Manuel (de zero às 24 horas nas bancas de jornais). Rio de Janeiro, 15 de julho de 1973.

\section{TACTICAL MEDIA FILES.}

Disponível em: http://www.tacticalmediafiles.net/n5m4/faq.jsp-faqid=programme.html. Acesso: 08/05/2020. 


\section{Sobre o(a) autor(a)}

Thiago Spíndola Motta Fernandes é historiador da arte, mestre e doutorando pelo Programa de Pós-Graduação em Artes Visuais da Universidade Federal do Rio de Janeiro na linha de pesquisa História e Crítica da Arte. Desenvolve pesquisas em arte contemporânea brasileira, crítica, teoria da imagem e intervenção urbana, com ênfase na virada do século XXI.

Contato: thiagosmfernandes@gmail.com

Orcid: https://orcid.org/0000-0001-9008-5447

Currículo Lattes: http://lattes.cnpq.br/5009686049893917

Recebido em: 14-05-2020 / Aprovado em: 30-06-2020

\section{Como Citar}

Fernandes, Thiago Spíndola Motta (2020). Mídia tática como conceito operativo nas artes visuais. Revista Estado da Arte, Uberlândia. v.1, n.1, p. 147-163, jan./jun. 2020. https://doi.org/10.14393/EdA-v1-n1-2020-54743 